\title{
The Effect of Adsorbed Oxygen on the Stability of NCO on Rh(111) Studied by Reflection Absorption Infrared Spectroscopy
}

\author{
János Kiss and Frigyes Solymosi \\ Institute of Solid State and Radiochemistry, Attila József University and Reaction Kinetics Research Group of the Hungarian \\ Academy of Sciences, ${ }^{1}$ P.O. Box 168, H-6701 Szeged, Hungary
}

Received June 9, 1998; revised June 9, 1998; accepted June 15, 1998

The interaction of HNCO with $\mathrm{Rh}(111)$ has been studied with reflection absorption infrared spectroscopy. HNCO adsorbs dissociatively on $\mathrm{Rh}(111)$ at $150 \mathrm{~K}$ to yield adsorbed $\mathrm{H}$ and NCO species. On clean Rh(111) the NCO species was found to decompose readily to adsorbed $\mathrm{CO}$ and $\mathrm{N}$ on warming to room temperature. Preadsorbed oxygen atoms result in an increase in the relative amount of NCO, shifts the dominant vibrational band of NCO from 2160 to $2182 \mathrm{~cm}^{-1}$, and significantly stabilizes the NCO species on Rh(111). The possible relevance of the stabilization of $\mathrm{NCO}$ in the $\mathrm{NO}+\mathrm{CO}$ reaction is discussed. (c) 1998 Academic Press

Key Words: $\mathrm{NO}+\mathrm{CO}$ reaction; adsorption of $\mathrm{HNCO}$; NCO surface complex; decomposition of NCO; effects of coadsorbed oxygen; stabilizing effect of oxygen adatoms; reflection absorption infrared spectroscopy.

\section{INTRODUCTION}

In the clarification of the mechanism of catalytic reactions it is of fundamental importance to establish the nature and the reactivity of surface complexes formed on the catalyst surface. In the case of the $\mathrm{NO}+\mathrm{CO}$ reaction the formation of isocyanate (NCO) surface species was observed on supported metals $(1,2)$. Due to the great technological importance of the reaction this observation was followed by extensive research with the aim to disclose more details on the formation of isocyanate complex and on its role in the catalytic reduction of NO. The results obtained strongly suggested that isocyanate plays an important role in the undesired formation of ammonia during automobile exhaust catalysis (1-6).

Subsequent studies, however, revealed several surprising features of adsorbed NCO species, namely that the amount of NCO greatly exceeds the number of surface metal atoms available (6), and the location of NCO bands in the infrared spectra (6-11), together with the reactivity of NCO species $(6,10,11)$, are primarily determined by the nature of the support. These observations led to the conclusion that although

\footnotetext{
${ }^{1}$ This laboratory is a part of the Center for Catalysis, Surface and Material Sciences at the University of Szeged.
}

isocyanate is formed on the metals, it migrates onto the support and becomes stabilized there (6-13). This conclusion was confirmed by IR spectroscopic measurements (14-17). As a consequence of this finding, isocyanate was no longer considered as a reaction intermediate of the $\mathrm{NO}+\mathrm{CO}$ reaction (18-20). This is obviously true for isocyanate located and stabilized on the support, but it remains an open question whether $\mathrm{NCO}$ primarily formed on and bonded to the metals cannot participate in the NO-CO reaction.

In harmony with the behaviour of a real reaction intermediate, this NCO species should have a short lifetime at high temperatures and low concentration; its identification, as well as the study of its chemistry, should therefore require sensitive spectroscopic techniques. This was clearly demonstrated in results obtained on unsupported metals, $\mathrm{Cu}\{111\}$ (21), $\operatorname{Pt}\{111\}(22), \operatorname{Pt}\{110\}(23), \operatorname{Rh}\{111\}$ (24), which showed that $\mathrm{NCO}$ (produced by the dissociation of $\mathrm{HNCO}$ ) on these metals is unstable and decomposes to adsorbed $\mathrm{CO}$ and $\mathrm{N}$ at around room temperature.

This observed instability of the isocyanate complex is rather surprising and apparently in contradiction with the experimental fact that both the $\mathrm{NO}+\mathrm{CO}$ reaction and the NCO formation proceed on supported Pt metals above 473$573 \mathrm{~K}$. This implies a significant lifetime and stabilization of NCO on Pt metals, even at such a high temperatures, before its migration onto the support where it accumulates. We assume that the key species in this phenomenon is adsorbed oxygen atoms formed in the $\mathrm{NO}+\mathrm{CO}$ reaction. The primary object of this work is to establish the effect of adsorbed oxygen on the vibrational characteristics and thermal stability of NCO species on Rh (111). For this purpose reflexion absorption infrared spectroscopy (RAIRS) is applied which-taking into account its high resolution and sensitivity - can be considered as an excellent method.

\section{EXPERIMENTAL}

The experiments were performed in a two-level UHV system with a base pressure of $5 \times 10^{-10}$ mbar. The lower part of the chamber had facilities for Auger electron 
spectroscopy (AES) and temperature-programmed desorption (TPD). The upper part was equipped with a single beam Fourier transform infrared spectrometer (Mathson Unicam, Research Series), which was used for RIAS measurements. All IR spectra were averaged over 512 scans using a MCT detector at $2-4 \mathrm{~cm}^{-1}$ resolution. Sample spectra were ratioed against a background taken immediately after the sample by flashing the crystal to $1270 \mathrm{~K}$. The scan was initiated after the crystal temperature had returned to $95 \mathrm{~K}$.

The $\mathrm{Rh}(111)$ single crystal was cleaned by cycled heating in oxygen. This was followed by cycles of argon ion bombardment (typically $1-2 \mathrm{kV}, 1 \times 10^{-4} \mathrm{~Pa}$ argon, $3 \mu \mathrm{A}$ for 10-30 $\mathrm{min}$ ) and by annealing at $1270 \mathrm{~K}$ for several minutes. Surface cleanliness was confirmed by AES. The Rh sample was resistively heated, and the temperature was measured with a chromel-alumel thermocouple spot-welded to the edge of the crystal. For low-temperature measurements the sample was cooled via a tantalum attached to a liquidnitrogen-cooled stainless steel tube. The adsorption of oxygen was performed at $300 \mathrm{~K}$. The surface concentration of oxygen on $\mathrm{Rh}(111)$ at saturation corresponds to 0.5 monolayer, $\Theta_{\mathrm{O}}=0.5$. The lower coverage oxygen overlayers were prepared by exposing the $\mathrm{Rh}(111)$ crystal to $\mathrm{O}_{2}$ for varying times at $300 \mathrm{~K}$. The amount of the surface oxygen was monitored by AES.

$\mathrm{HNCO}$ was prepared by the reaction of $95 \% \mathrm{H}_{3} \mathrm{PO}_{4}$ and saturated $\mathrm{KOCN}(8)$. It was degassed and purified by freezepump-thraw cycles.

\section{RESULTS AND DISCUSSION}

The RAIR spectrum of the $\mathrm{Rh}(111)$ surface exposed to various amounts of $\mathrm{HNCO}$ at $95 \mathrm{~K}$ is shown in Fig. 1A. At low exposure only one absorption band could be detected at $2267 \mathrm{~cm}^{-1}$. With the increase of the HNCO exposure the $2267 \mathrm{~cm}^{-1}$ band shifted to $2277 \mathrm{~cm}^{-1}$ and other absorption bands appeared at 3373, 3240, 1444, 1419, 1322, $1245 \mathrm{~cm}^{-1}$. Taking into account the vibrational characteristics of vapour and solid $\mathrm{HNCO}$ and those of adsorbed HNCO on oxides surfaces $(8,11,25)$, the strong band at $2267-2277 \mathrm{~cm}^{-1}$ is no doubt due to the asymmetric stretch of moleculary adsorbed HNCO. The assignment of the other bands are given in the Table 1 . It is remarkable that the bands due to N-H vibration appeared only at higher exposure, which may indicate that in the submonolayer the H-N axis (but not the $\mathrm{N}-\mathrm{C}-\mathrm{O}$ group) is paralell to the surface. It is also possible that the absence of the $v(\mathrm{~N}-\mathrm{H})$ band at low coverage could be due to its lower intensity, compared to other bands. Note that a weak band at $2160 \mathrm{~cm}^{-1}$ also appeared, which was attributed in our previous works to the asymmetric vibration of adsorbed NCO formed in the dissociation of $\mathrm{HNCO}(8,11)$. Alternatively, it may belong to the molecularly adsorbed $\mathrm{HNCO}$, as this weak band was
TABLE 1

Frequencies $\left(\mathrm{cm}^{-1}\right)$ and Assignments of the Fundamental Vibrations of Vapour, Solid and Adsorbed HNCO

\begin{tabular}{llrccc}
\hline & Assignment & Vapour & Solid & $\begin{array}{c}\text { Submonolayer } \\
\text { on Rh(111) }\end{array}$ & $\begin{array}{c}\text { Multilayer } \\
\text { on Rh(111) }\end{array}$ \\
\hline$v_{1}\left(\mathrm{a}^{\prime}\right)$ & $v(\mathrm{NH})$ & 3531 & 3133 & - & $3373 ; 3240$ \\
$v_{2}\left(\mathrm{a}^{\prime}\right)$ & $v_{\mathrm{a}}(\mathrm{NCO})$ & 2274 & 2246 & 2267 & 2277 \\
$v_{4}+v_{6}$ & & 1480 & 1460 & - & 1444 \\
$v_{4}+v_{5}$ & & 1371 & 1377 & - & 1419 \\
$v_{3}\left(\mathrm{a}^{\prime}\right)$ & $v_{\mathrm{s}}(\mathrm{NCO})$ & 1327 & 1326 & - & 1322 \\
$v_{4}\left(\mathrm{a}^{\prime}\right)$ & $\delta(\mathrm{NCO})$ & 797 & - & - & - \\
$v_{5}\left(\mathrm{a}^{\prime}\right)$ & hindered rotation & 572 & - & - & - \\
$v_{6}\left(\mathrm{a}^{\prime \prime}\right)$ & & 670 & - & - & - \\
\hline
\end{tabular}

Note. Data for HNCO in vapour and solid phase were taken from Ref. (25). $v_{4}+v_{6} ; v_{4}+v_{5}$ correspond to combinations of fundamental vibrations.

also seen in the IR spectrum of HNCO vapour (25). When the sample was heated to $150-175 \mathrm{~K}$, the $2267 \mathrm{~cm}^{-1}$ band $\left(v_{\mathrm{a}}, \mathrm{NCO}\right)$, and the band at $3240 \mathrm{~cm}^{-1}(v \mathrm{~N}-\mathrm{H})$, both indicative of the presence of molecularly adsorbed HNCO, were completely eliminated. At the same time the peak at $2160 \mathrm{~cm}^{-1}$ intensified and a new peak developed at $\sim 2020 \mathrm{~cm}^{-1}$. There is no doubt that this $2160 \mathrm{~cm}^{-1}$ band is due to NCO species, while the band at $2020 \mathrm{~cm}^{-1}$ is the vibration of adsorbed $\mathrm{CO}$ produced by the decomposition of NCO complex. Further increase in the annealing temperature led to the attenuation of the $2160 \mathrm{~cm}^{-1}$ band and to the intensification of the $\mathrm{CO}$ band. In agreement with the results of previous works, the band indicative of the presence of the adsorbed NCO completely disappeared between 300-330 K (24).

TPD measurements indicated that the weakly adsorbed HNCO desorbed with a peak temperature of $118 \mathrm{~K}$, which shifted to $125 \mathrm{~K}$ at higher exposures. This peak cannot be saturated, which is the sign of the formation of a condensed layer. In addition to $\mathrm{HNCO}$, the formation of $\mathrm{CO}$ with $T_{\mathrm{p}}=$ $440 \mathrm{~K}$, and $\mathrm{N}_{2}$ with $T_{\mathrm{p}}=630$ and $720 \mathrm{~K}$ also occurred. These peak temperatures agree well with those found following the adsorption of $\mathrm{CO}$ (27) and $\mathrm{N}$ atoms (28) on $\mathrm{Rh}(111)$ surface, suggesting that the evolution of these compounds is desorption limited reaction. TPD data are collected in Table 2.

The same experiments have been performed on oxygendosed $\mathrm{Rh}$. The molecularly adsorbed HNCO gave identical spectral features as obtained for the clean surface. The position of the NCO species, however, shifted to higher frequencies. In order to see more clearly, the adsorption of $\mathrm{HNCO}$ was performed at $150 \mathrm{~K}$, above the desorption temperature of HNCO. The effect of oxygen coverage is shown in Fig. 2A. At lower oxygen coverages, two peaks can be distinguished at 2160 and $2180 \mathrm{~cm}^{-1}$. At the highest oxygen coverage we obtained only one peak at $2182 \mathrm{~cm}^{-1}$. The 

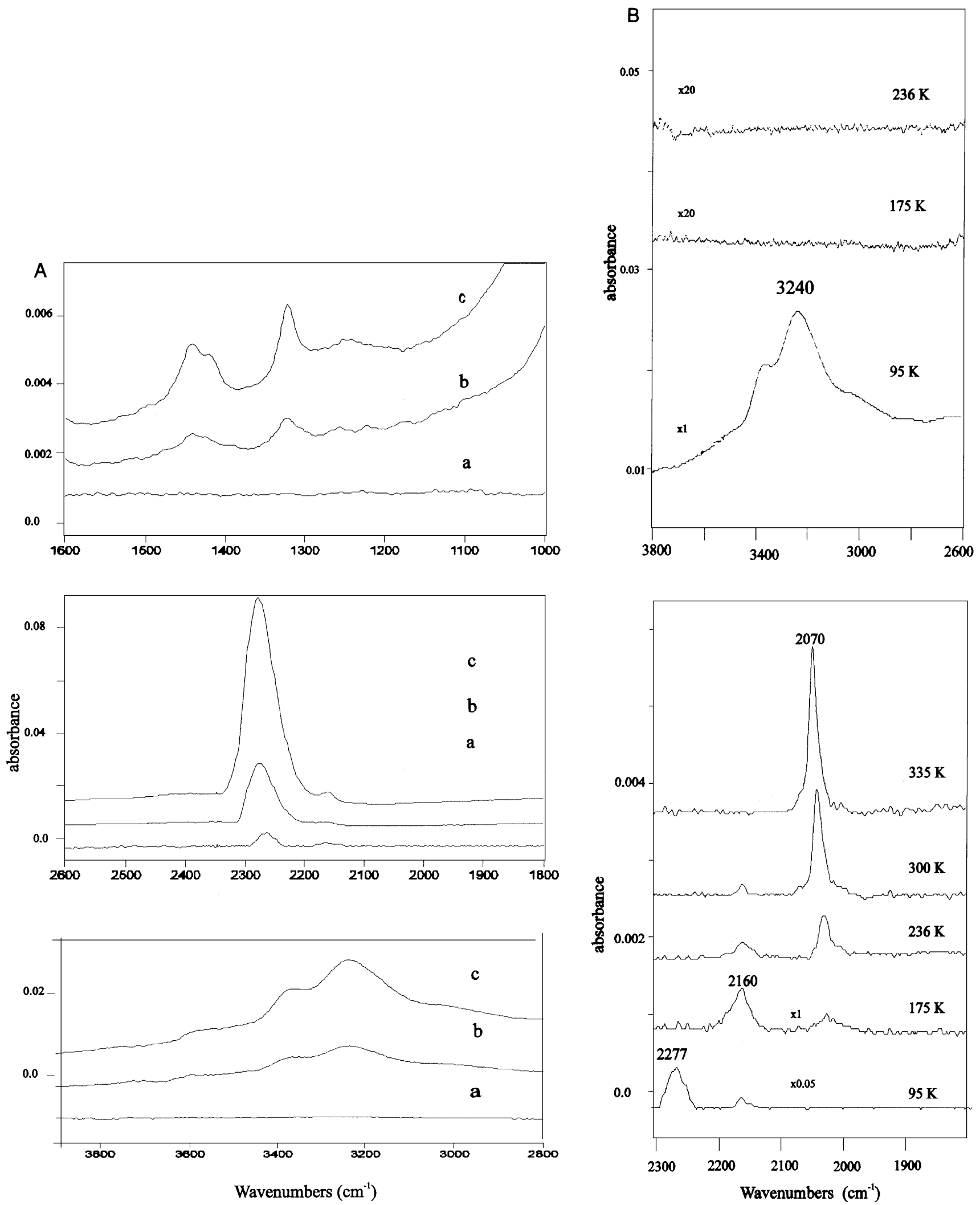

FIG. 1. (A) RAIR spectrum of adsorbed HNCO as a function of HNCO exposures on a clean Rh(111) at $95 \mathrm{~K}$ : (a) 6L; (b) 18L; (c) $30 \mathrm{~L}$. (B) Effects of annealing of the adsorbed layer. 
TABLE 2

Characteristic TPD Data Following the Adsorption of HNCO on Clean and O-Dosed Rh(111) at $\sim 95 \mathrm{~K}$

\begin{tabular}{lcc}
\hline & \multicolumn{2}{c}{ Peak temperature (K) } \\
\cline { 2 - 3 } Product & Clean $\mathrm{Rh}(111)$ & Oxygen covered $\mathrm{Rh}(111) \Theta_{\mathrm{O}} \sim 0.5$ \\
\hline $\mathrm{HNCO}$ & $118-125$ & $118-125$ \\
$\mathrm{CO}$ & 440 & 460 \\
$\mathrm{~N}_{2}$ & $630 ; 720$ & $630 ; 720$ \\
$\mathrm{H}_{2}$ & 420 & - \\
$\mathrm{CO}_{2}$ & - & 390 \\
$\mathrm{H}_{2} \mathrm{O}$ & - & 185 \\
\hline
\end{tabular}

effect of annealing is displayed in Fig. 2B. Around $200 \mathrm{~K}$, an intense $\mathrm{CO}$ band appeared at $2060 \mathrm{~cm}^{-1}$. On further heating of the sample, the NCO band attennuated and the $\mathrm{CO}$ band became more intense. The spectral feature centered at $2182 \mathrm{~cm}^{-1}$ disappeared only at $373 \mathrm{~K}$, a significantly higher temperature than in the case of a clean surface. This suggests that preadsorbed oxygen enchances the stability of the isocyanate complex on Rh surface. This is clearly demonstrated by the intensity data versus annealing temperature in Fig. 3.

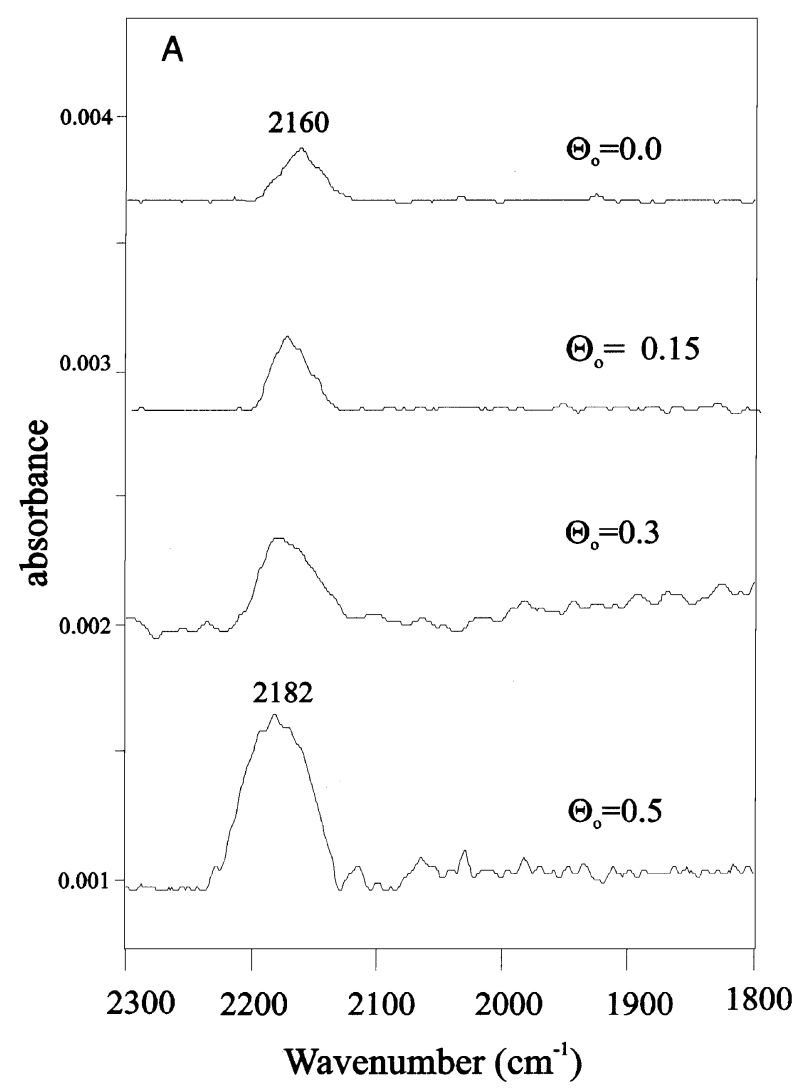

By means of TPD we detected the same desorbing products, $\mathrm{CO}$ and $\mathrm{N}_{2}$, as for the clean surface. In addition, the release of $\mathrm{H}_{2} \mathrm{O}\left(T_{\mathrm{P}}=185 \mathrm{~K}\right)$ and $\mathrm{CO}_{2}\left(T_{\mathrm{P}}=390 \mathrm{~K}\right)$ was also established. Taking into account that above $300 \mathrm{~K}$ both the $\mathrm{NCO}$ and $\mathrm{CO}$ are present on the surface it is likely that both compounds participate in the reaction with adsorbed $\mathrm{O}$. The formation of $\mathrm{CO}_{2}$ is clearly a reaction-limited process, as $\mathrm{CO}_{2}$ desorbs from a clean $\mathrm{Rh}(111)$ far below $300 \mathrm{~K}$ (29).

For the stabilizing effect of adsorbed $\mathrm{O}$ atoms several reasons can be considered: (i) The NCO species is affected by a strong electric field induced by adsorbed oxygen atoms (30-32). Recently Kreuzer (31-32) has shown that the binding of adsorbed species to the surface can be strongly influenced in an external field. As a result of this effect, NCO species can be converted into a more ionic form, leading to higher stability. Previous IR data show that the increasing stability of surface NCO adsorbed on a series of oxides is reflected in an increase in NCO frequency $(8,11)$. (ii) Oxygen adatoms could block sites for the formation of the dissociation products, $\mathrm{CO}(\mathrm{a})$ and $\mathrm{N}(\mathrm{a})$. It is conceivable that the combined influence of these factors lead to the stabilization of the NCO species. It is also possible that preadsorbed oxygen changes the adsorption sites for NCO. The direction and the extent of the shift of the NCO vibrational band due

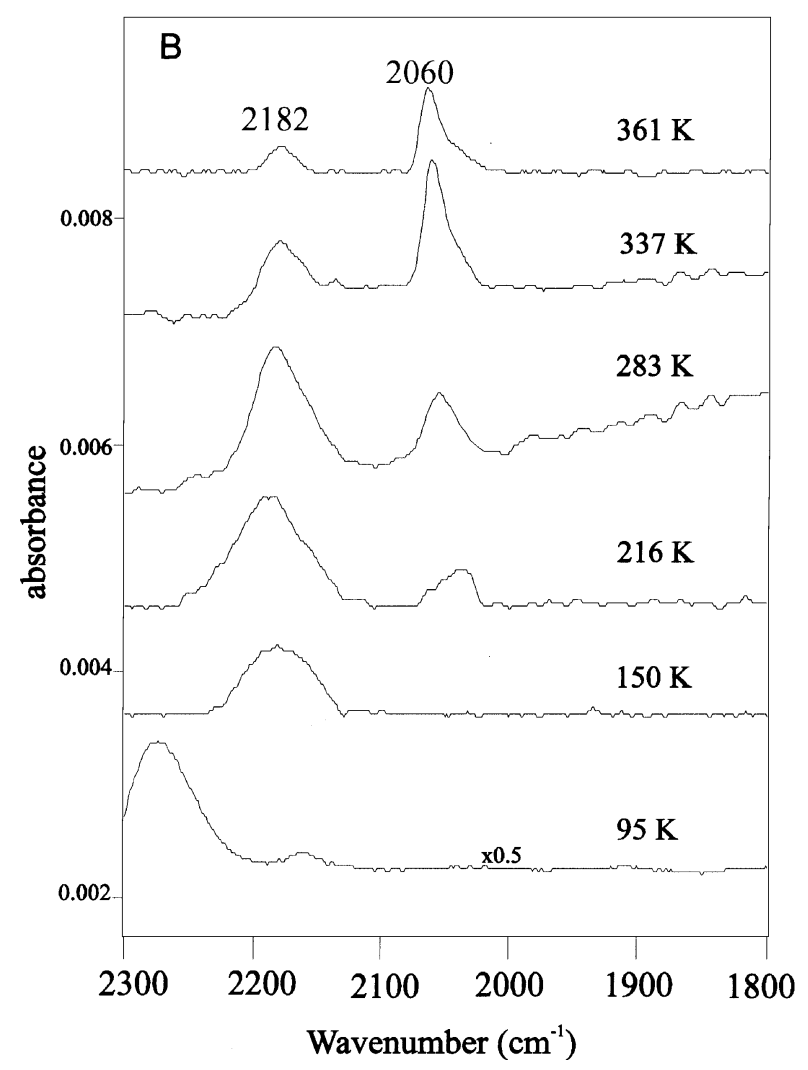

FIG. 2. (A) Effects of oxygen coverage on the RAIR spectrum of adsorbed NCO on Rh(111) at $150 \mathrm{~K}$. (B) Effects of annealing of HNCO + $\mathrm{O} / \mathrm{Rh}(111)$ system $\left(\Theta_{\mathrm{O}} \approx 0.5\right)$. Adsorption temperature was $95 \mathrm{~K}$. 


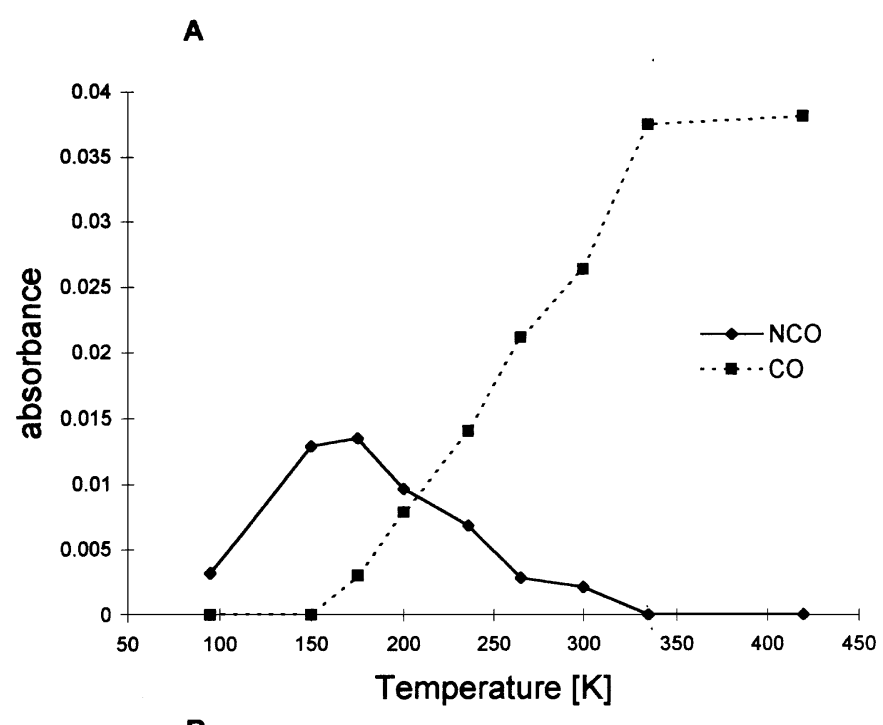

B

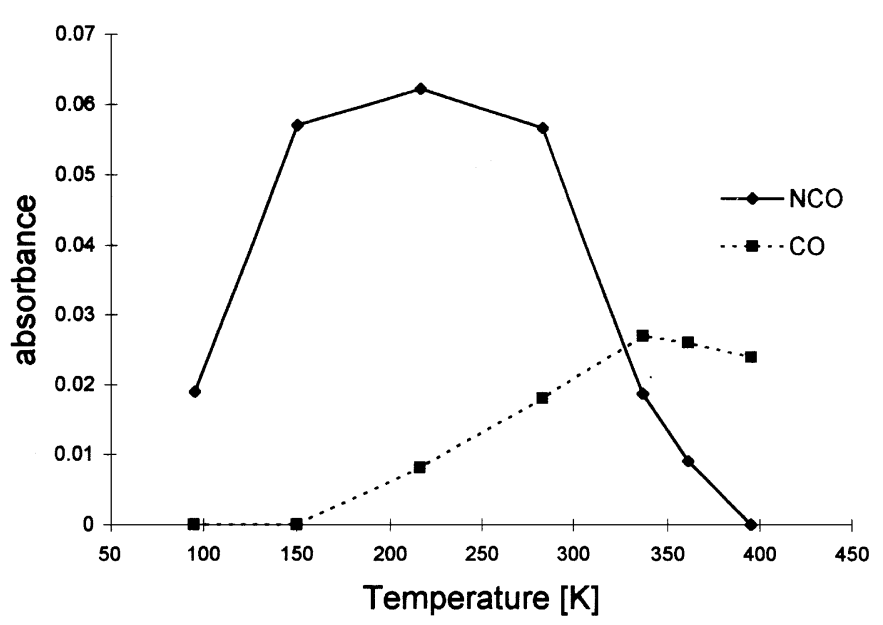

FIG. 3. The intensity changes of vibrational bands at $2160-2182 \mathrm{~cm}^{-1}$ (NCO) and 2020-2070 $\mathrm{cm}^{-1}$ (CO) after heating the clean (A) and oxygendosed samples (B) saturated with $\mathrm{HNCO}$ at $95 \mathrm{~K}$. All vibrational spectra were taken after the crystal again cooled to ca $95 \mathrm{~K}$.

to adsorbed oxygen atoms, however, do not support this assumption.

We may compare the features observed with those established recently by Menzel et al. $(33,34)$. They succeeded for the first time to produce $\mathrm{NCO}$ species by the $\mathrm{NO}+\mathrm{CO}$ reaction on a single crystal, $\mathrm{Ru}(001)$, under UHV conditions. The NCO gave a vibrational band at $2170 \mathrm{~cm}^{-1}$ in the HREEL spectrum. An important finding of this work is that the presence of adsorbed oxygen is a necessary condition for the production of NCO. For pure $(\mathrm{N}+\mathrm{CO})$ layers isocyanate formation was not observed. Furthermore, the production of NCO depended strongly on the structure of the preadsorbed $(\mathrm{N}+\mathrm{O})$ layer. In explaining these results, the influence of an electrostatic field due to O-induced dipoles on the $(\mathrm{N}(\mathrm{a})+\mathrm{CO}(\mathrm{a}))$ layer, and the O-induced changes of the adsorption properites of $\mathrm{Ru}(001)$ were taken into account. In the light of our results, it is very likely that the stabilizing effect of oxygen atoms also contributes to the existence and identification of the NCO species on $\mathrm{Ru}(001)$. Interestingly, when $\mathrm{NCO}$ was produced under optimum conditions (heating of the disordered $(\mathrm{N}+\mathrm{CO})$ layer), $\mathrm{NCO}$ gave a vibrational band at $2190 \mathrm{~cm}^{-1}$ and of higher intensity; this loss was detectable at a higher temperature than the $2170 \mathrm{~cm}^{-1}$ loss observed following heating of the ordered layer $(33,34)$. These features are in agreement with our findings and we feel they are strongly associated with the effects of adsorbed oxygen atoms established in this work.

Finally, we mention that the NCO surface complex has also been detected in the reduction of the NO pollutant with saturated and unsaturated hydrocarbons on supported $\mathrm{Cu}$ catalysts. Yoshida et al. $(35,36)$ found a correlation between the efficiency of $\mathrm{NO}_{x}$ reduction and the formation of the NCO species. They concluded that the NCO intermediate and/or its reaction with $\mathrm{NO}$ are a key to efficient NO reduction in the presence of oxygen. In a recent study it was also shown that NCO is more stable on copper that on Pt metals, and the migration onto the support is more restricted (37). Isocyanate species were also identified on oxidized $\mathrm{Pt}$ metals in the catalytic reaction of $\mathrm{NH}_{3}$ and $\mathrm{CO}$, which is connected with the synthesis of compounds important for the fertilizer industry $(16,17)$. We believe that in both cases the stabilizing effect of adsorbed oxygen plays an important role in the appearance and identification of NCO species.

On summing up we can assume that, under dynamic conditions, due to this stabilizing effect, the NCO surface species has a sufficient lifetime on $\mathrm{Rh}$, even at a higher temperature, for it to function as a surface intermediate in the main and side-reactions during automobile exhaust catalysis. Further studies are clearly required under dynamic conditions.

\section{CONCLUSIONS}

HNCO adsorbs dissociatively on a clean Rh(111) surface above $150 \mathrm{~K}$. The NCO species formed is characterized by an intense loss feature at $2160 \mathrm{~cm}^{-1}$ on a clean and $2182 \mathrm{~cm}^{-1}$ on an oxygen-dosed $\mathrm{Rh}(111)$ surface in the RAIR spectrum. The NCO surface complex decomposes almost completely on clean $\mathrm{Rh}$ at around $300 \mathrm{~K}$ under UHV conditions. Oxygen adatoms enhance its stability region at least by $60 \mathrm{~K}$. Although the detailed reaction kinetics of the $\mathrm{CO} / \mathrm{NO}$ oxidation reaction to $\mathrm{CO}_{2}$ over $\mathrm{Rh}$ can be described with a scheme involving NO dissociation (38), where NCO plays no part, it is likely that under dynamic conditions NCO exists on the Rh catalysts even at higher temperatures and may be involved in important side reactions.

\section{ACKNOWLEDGMENTS}

This work is supported by Hungarian Academy of Sciences and by the OTKA Grant 23023. 


\section{REFERENCES}

1. Unland, M. L., J. Catal. 31, 459 (1973).

2. Unland, M., J. Phys. Chem. 77, 1952 (1973).

3. Solymosi, F., and Sarkany, J., Appl. Surf. Sci. 3, 68 (1979).

4. Voorhoeve, R. J. H., and Trimble, L. E., J. Catal. 38, 80 (1975).

5. Solymosi, F., and Rasko, J., J. Catal. 49, 240 (1977).

6. Solymosi, F., Kiss, J., and Sarkany, J., in "Proc. of 3rd Intern. Conference on Solid Surfaces, Vienna, 1977" (R. Dobrozemsky, Ed.), p. 819.

7. Lorimer, F., and Bell, A. T., J. Catal. 59, 223 (1979).

8. Solymosi, F., and Bansagi, T., J. Phys. Chem. 83, 552 (1979).

9. Dalla Betta, R. A., and Shelef, M., J. Mol. Catal. 1, 431 (1976).

10. Solymosi, F., Sarkany, J., and Volgyesi, L., J. Catal. 54, 336 (1978).

11. Solymosi, F., Volgyesi, L., and Sarkany, J., Z. Phys. Chem. N.F. 120, 79 (1980).

12. Bansagi, T., Rasko, J., and Solymosi, F., in "Proc. of Intern. Symposium on Spillover of Adsorbed Species, Lyon, 1983," p. 109.

13. Keller, W. C., and Bell, A. T., J. Catal. 59, 200 (1983).

14. Novak, E., and Solymosi, F., J. Catal. 125, 112 (1990).

15. Dictor, R., J. Catal. 109, 89 (1988).

16. Paul, D. K., Worley, S. D., Hoffman, N. W., Ash, D. H., and Gauney, J., Chem. Phys. Letts. 160, 559 (1989).

17. Paul, D. K., Worley, S. D., Hoffman, N. W., Ash, D. H., and Gauney, J., Surf. Sci. 223, 509 (1989).

18. Root, T. W., Fisher, G. B., and Schmidt, L. D., J. Chem. Phys. 85, 4687 (1986).

19. Belton, D. A., and Schmieg, S. J., J. Catal. 144, 9 (1993).
20. Veser, G., and Imbihl, R., Surf. Sci. 269(27), 465 (1992).

21. Solymosi, F., and Kiss, J., Surf. Sci. 104, 181 (1981).

22. Gorte, R. J., Schmidt, L. D., and Sexton, B. A., J. Catal. 67, 387 (1981).

23. Solymosi, F., and Kiss, J., Surf. Sci. 108, 641 (1981).

24. Solymosi, F., and Kiss, J., Surf. Sci. 135, 243 (1983).

25. Hertzberg, G., and Reid, C., Discuss. Faraday Soc. 9, 92 (1950). [Reid, C., Chem. J. Phys. 181544 (1950)]

26. Nelson, F., and Nelson, S. M., J. Chem. Soc. A. 1597 (1969).

27. Yates, J. T., Williams, E. D., and Weinberg, W. H., Surf. Sci. 91, 562 (1981).

28. Berkó, A., and Solymosi, F., Appl. Surf. Sci. 55, 193 (1992).

29. Kiss, J., Révész, K., and Solymosi, F., Surf. Sci. 207, 36 (1988).

30. Holloway, S., Norskov, J. K., and Lang, N. D., J. Chem. Soc. Faraday Trans. I 83, 1935 (1987).

31. Kreuzer, H. J., in "Chemistry and Physics of Solid Surfaces" (R. Vanselow and R. Howe, Eds.), p. 133, Springer, Berlin, 1990.

32. Kreuzer, H. J., and Wang, L. C., J. Chem. Phys. 93, 6065 (1990).

33. Kostov, K. L., Jacob, P., Rauscher, H., and Menzel, D., J. Phys. Chem. 95, 7785 (1991).

34. Kostov, L., Rauscher, H., and Menzel, D., Surf. Sci. 287/288, 283 (1993).

35. Ukiso, Y., Sata, S., Muramatsu, G., and Yoshida, K., Catal. Lett. 11, 177 (1991). and 16, 11 (1992).

36. Ukiso, Y., Sata, S., Abe, A., and Yoshida, K., Appl. Catal. B2, 147 (1993).

37. Solymosi, F., and Bansagi, T., J. Catal. 156, 75 (1995).

38. King, D. A., Surf. Rev. and Letters 1, 435 (1994). 